\title{
IMPLICIT RECOGNITION IN PURE ALEXIA: THE SAFFRAN EFFECT-A TALE OF TWO SYSTEMS OR TWO PROCEDURES?
}

\author{
Matthew A. Lambon Ralph, Anne Hesketh, and Karen Sage \\ University of Manchester, UK
}

\begin{abstract}
Some patients with pure alexia or letter-by-letter reading demonstrate the Saffran effect: residual activation of higher order lexical-semantic representations despite poor word recognition. This study investigated the reading of patient FD, a letter-by-letter reader with a clear Saffran effect. Two alternative explanations for this effect were tested in a series of experiments and through the impact of whole-word and letter-based therapies on FD's reading. One theory assumes that the disparity between overt recognition and implicit activation of word meaning is underpinned by two separate reading systems. An alternative hypothesis argues for a single whole-word reading system supplemented by the deliberate, compensatory strategy of letter-by-letter reading. Under this hypothesis, the Saffran effect reflects partial activation of the single, whole-word system.

FD's results strongly supported the latter hypothesis. FD's reading behaviour was characterised by partial activation of higher word representations, accuracy was graded by word variables known to influence the normal reading system, and most importantly, once the characteristics of the tasks were equated, there was no evidence for a dissociation between word categorisation and recognition. In addition, the whole-word therapy encouraged FD to abandon the letter-by-letter strategy. Without this compensatory technique, FD's emergent deep dyslexia was consistent with a partially activated, whole-word reading system that produces overt reading responses. Comparison of data from this and other studies suggests that the Saffran effect is most likely to be observed in patients with severe pure alexia.
\end{abstract}

\section{INTRODUCTION}

Although reports of "preserved" or "implicit" word recognition in pure and global alexics first appeared in the literature over 40 years ago (Kreindler \& Ionasescu, 1961), the first comprehensive investigation of such patients was reported by Shallice and Saffran (1986). This study was followed by a series of papers predominantly by Saffran and her colleagues (Coslett \& Saffran, 1989a; Coslett, Saffran, Greenbaum, \& Schwartz, 1993; Saffran \& Coslett, 1998). The clinical manifestation of this phenomenon (hereinafter referred to as the Saffran effect) is of patients who are able to indicate the meaning of written words, or their lexical status, despite being unable to give the exact identity of the words themselves-i.e., read them aloud. Early studies described patients with very impoverished reading (global alexics) who were able to perform above chance on word-picture

Correspondence should be addressed to Prof M. A. Lambon Ralph, Dept. of Psychology, University of Manchester, Oxford Road, Manchester, M13 9PL, UK (Email: matt.lambon-ralph@man.ac.uk).

We thank Eleanor Saffran not only for the inspiration to conduct this study but also for providing us with materials from her implicit recognition experiments. We are also indebted to FD and his family for their generous donations of time and effort. 
matching tasks or in forced-choice semantic decisions (Albert, Yamadori, Gardner, \& Howes, 1973; Caplan \& Hedley-Whyte, 1974; Landis, Regard, \& Serrat, 1980). While these initial reports are striking, the amount of data presented was minimal. The first detailed investigation of the Saffran effect was on patient ML (Shallice \& Saffran, 1986). ML, a slow letter-by-letter reader, was able to perform above chance on a series of forced-choice lexical decision and categorisation tasks even when the words were presented too briefly for ML to report overtly the identity of the word or its constituent letters. Subsequent descriptions of other patients found a similar disparity between above-chance performance under brief presentation and little or no explicit word recognition (for an overview, see Saffran \& Coslett, 1998). Having presented each word for a duration of around $250 \mathrm{~ms}$, these patients typically performed in the range of $60-80 \%$ correct on various twoalternative forced-choice lexical decision or semantic categorisation tasks. While this level of performance is significantly above that expected by chance, as far as we are aware, no patient has been reported to show normal ability on these simple reading tasks (i.e., at, or close to, perfect performance).

The ability to categorise words without overtly recognising them is, perhaps, the most striking form of the Saffran effect. There is a range of other results that also suggest activation of higher level, lexical-semantic representations in pure alexic patients. For instance, some letter-by-letter readers have exhibited the word superiority effect (better letter recognition under masked presentation if the stimuli correspond to words, or wordlike nonwords, than letter strings: Reuter-Lorenz \& Brunn, 1990). In addition, pure alexics show influences of variables associated with lexicalsemantic processes (frequency and imageability: Behrmann, Plaut, \& Nelson, 1998b) and can also demonstrate standard Stroop interference (McKeeff \& Behrmann, 2004 this issue).

There is an ongoing debate about the locus of impairment that gives rise to pure alexia (Coltheart, 1998). Some researchers suggest that pure alexia reflects damage to a general visual system (Behrmann, Nelson, \& Sekuler, 1998a; Farah \& Wallace, 1991; Mycroft, Behrmann, \& Kay, 2003), others argue that there is impaired letter recognition or a breakdown between letter and word representations (e.g., Patterson \& Kay, 1982). The explanations all share the notion, however, that pure alexia reflects a relatively early impairment in the visual-orthographic system that leads to poor whole-word recognition. By way of compensation, patients resort to a letter-by-letter reading strategy. At face value, explanations of pure alexia based on early visual impairment seem at odds with the Saffran effect: The early visual deficit is supposed to prevent activation of wholeword representations, thus necessitating the letterby-letter strategy for word recognition but the Saffran effect is evidence for activation of highlevel representations including word meaning.

There are two rival explanations for the Saffran effect in the literature, both of which were first discussed in detail by Shallice and Saffran (1986). The first explanation, championed by Saffran, Coslett, and their colleagues (Saffran \& Coslett, 1998), separates the key behavioural elements observed in these patients and posits a separate system for each one. Their theory is based on the notion that there are two parallel reading systems, one in each hemisphere of the brain. The left hemisphere system supports explicit letter and word recognition and, when damaged, uses letterby-letter reading as a compensatory strategy. The right hemisphere reading system underpins implicit letter and word recognition. When the left hemisphere system is damaged, as it is in pure alexic patients, their letter-by-letter behaviour is derived from the remaining processing in the left hemisphere while the Saffran effect is generated by the right hemisphere. The separation of processing in these systems is further reinforced by the notion that the left hemisphere system can inhibit the right hemisphere. The early report by Landis et al. (1980) noted that their patient's implicit reading disappeared once letter recognition had recovered sufficiently to support letter-by-letter reading. Likewise, Coslett et al. (1993) reported data from patient JWC, who was able to switch between letter-by-letter reading when the task required 
explicit word identification and whole-word (implicit) recognition for categorisation tasks. In addition, Coslett and Saffran (1989a) were able to demonstrate that performance on categorisation tasks declined as the exposure length was increased from $250 \mathrm{~ms}$ to $2 \mathrm{~s}$ and it was at this point that the patients were able to engage a letter-by-letter strategy.

Various aspects of the two systems hypothesis have been challenged. The implicit versus explicit distinction was questioned by Feinberg, Dyches-Berke, Miner, and Roane (1994). The patient they described exhibited the Saffran effect but Feinberg et al. argued that her accuracy on various categorisation tasks matched the level of her explicit awareness and was consistent with degraded, partial semantic access from orthography. Coslett and Saffran (1989a) found that with repeated exposure to brief presentation experiments, over several weeks, their patients began to read some words explicitly and without recourse to letter-by-letter reading. Further investigation found that this explicit reading performance (still under brief presentation conditions) was influenced by factors such as imageability and part-ofspeech effects-i.e., the patients demonstrated some features of phonological-deep dyslexia, although they did not produce semantic paralexias. A combined pure-deep dyslexic, described by Buxbaum and Coslett (1996), is of added interest because he had a number of features in common with the case described in this study. At unlimited exposure, the patient used a laborious letter-byletter strategy, exhibited an imageability and partof-speech effect, and had very poor nonword reading. These effects remained unchanged if the words were presented briefly $(100 \mathrm{~ms})$ except that the patient produced a significantly greater number of semantic paralexias.

Although some researchers have argued that the letter-by-letter strategy inhibits the separate reading system that underpins the Saffran effect (Landis et al., 1980; Saffran \& Coslett, 1998), other results suggest that these two phenomena can co-occur. For instance, in a thorough review of the pure alexia literature and of newly collected data, Behrmann et al. (1998b) found that pure alexics' length-reading time function was also influenced by frequency and imageability. The dual influence of length and lexical-semantic factors suggests that, to at least some extent, whole-word reading processes and the letter-byletter strategy are working in parallel or in conjunction.

These results and the Saffran effect can be explained by an alternative, two "processes" theory. This explanation assumes that impaired visual input drives two processes: a single whole-word recognition system and a separate, compensatory letter-by-letter strategy (Behrmann et al., 1998b; Shallice \& Saffran, 1986). This contrasts with the two systems hypothesis, which duplicates elements in the left and right hemispheres for whole-word recognition (the two systems) and also includes a separate, compensatory letter-by-letter strategy (which is assumed to be underpinned by the left hemisphere). In effect, there are three processesleft-hemisphere, overt whole-word reading (which is abolished in pure alexia), right-hemisphere reading (that supports covert recognition), and left-hemisphere letter-by-letter reading. Under the two processes/single system hypothesis, patients' reading behaviour, with unlimited exposures, reflects the conjoint action of these two processes. Although slow and laborious, letter-byletter reading allows for accurate word identification, which is boosted by the whole-word system if the words are common and concrete (Behrmann et al., 1998b). With more severe impairment, the conjoint action of the two processes is reflected in patients who exhibit features of both pure and deep dyslexia (Buxbaum \& Coslett, 1996). However, letter-by-letter reading is limited or impossible with brief presentation and, as a deliberate compensatory strategy, patients can learn to avoid or inhibit the technique altogether (Coslett \& Saffran, 1989a).

Under this proposal, the Saffran effect simply reflects the partial, remaining activation of the whole-word recognition system (Behrmann et al., 1998b; Feinberg et al., 1994; Shallice \& Saffran, 1986). This also explains why performance on lexical decision and categorisation tasks is above chance but never perfect in these cases. The 
combination of early visual-orthographic impairments and partial semantic access is only surprising if the reading system contains discrete processes. In a cascading or interactive activation system, impaired input will still produce partial, degraded activation in the post-impairment processes (Morton \& Patterson, 1980; Shallice \& Saffran, 1986). In McClelland and Rumelhart's (1981) interactive activation word recognition model, reduced input to letter features still produced partial letter and word level activation. This was, of course, the basis for their explanation of the word superiority effect in normal readers under masked, brief presentation. Likewise, it explains why pure alexics can also show the word superiority effect (feedback from lexical-semantic knowledge), effects of frequency and imageability (frequent and concrete words are more readily activated even under reduced visual input) and above-chance performance on lexical decision and categorisation tasks (partial activation of lexical and semantic representations). If the Saffran effect does emerge from the normal, premorbid whole-word reading system under reduced or degraded visual input, then this theory also explains why categorisation performance is influenced by the same factors as timed word reading. Shallice and Saffran (1986), for example, demonstrated that patient ML's lexical decision performance was influenced by the wordlikeness of the nonword foils and the frequency of the real words.

A key, unresolved question is why only some patients show the Saffran effect. While a number of patients show above-chance performance on categorisation and lexical decision tasks (Saffran \& Coslett, 1998), others do not (e.g., Patterson \& Kay, 1982). In a similar vein, Behrmann et al. (1998b) note that the influence of frequency and imageability varies across patients. Three explanations of these differences have been proposed. The first is methodological. Saffran and Coslett (1998) argued that pure alexic patients can be reluctant to relinquish the letter-by-letter strategy and to make a binary decision when the word is merely flashed in front of them. Patients have to be encouraged, therefore, to make responses or even guesses in these somewhat strange, experimental conditions.
While this might be a reason for the failure to find above-chance categorisation in brief presentation tasks, it seems less likely as an explanation for the variation in frequency and imageability effects in pure alexia. Letter-by-letter reading times are presumably boosted automatically by underlying lexical-semantic representations. The second explanation is that the Saffran effect might vary across individual patients according to the presence of other concurrent impairments. So, for example, if some pure alexic patients have additional lexicalsemantic deficits, then the functioning of the whole-word recognition system may be compromised and the influence of frequency and imageability reduced or even abolished. The final explanation is based on severity. Behrmann and colleagues (1998b) argued that with very mild visual impairment, word recognition might require little if any assistance from higher-order representations. With very severe impairments, there may be so little input to the whole-word recognition system that the degree of feedback activation is minimal or non-existent. In between, however, moderately degraded visual processing benefits considerably from feedback activation. In support of this hypothesis, Behrmann et al. found that the size of frequency and imageability effects in their pure alexic patients were significantly correlated with the slope of the length-reading time function.

In this study we describe a letter-by-letter reader who demonstrated the Saffran effect. The investigations were designed to test the contrasting predictions of the two systems and two processes hypotheses, and to assess the explanations for why the Saffran effect varies across individual patients.

\section{PATIENT STUDY}

\section{Background}

\section{Social and medical history}

FD was born in 1924. Prior to retirement, he had held a variety of jobs including running a grocer's shop and working for a tyre company. FD was also a Jehovah's Witness. This had two important influences on the present study. First, as reading is 
a key activity within this faith, FD and his family were highly motivated to undertake extensive assessment and therapy programmes, despite FD's severe alexia. Second, FD's extensive experience of the Jehovah's Witness literature meant that Christian religious terms were extremely familiar to him - a factor made use of in two of the experiments reported below.

In 1995 and 1996, FD had suffered two minor cerebral vascular accidents. These did not lead to hospitalisation but FD was clinically managed at home. In the acute phase FD was noted to have a mild left hemiparesis, which later resolved, and a 24-hour period of "broken sentences" and poor comprehension of simple questions. In August 1997, FD was admitted to hospital with speech difficulty and memory loss. A CT scan (see Figure 1) showed an extensive haemorrhagic infarct in the left parietal lobe extending inferiorly into the temporal lobe. This also revealed evidence of the two previous vascular incidents with old infarcts in the right parietal and right occipital regions. In September 1997, FD underwent a right carotid endocardectomy and was discharged a week later. Unfortunately, FD was readmitted in midOctober with a frontal headache and loss of vision. A new CT scan (see Figure 1) showed an additional left occipital haematoma and a fresh bleed in the occipital horn of the right lateral ventricle. Medical examination revealed right hemianopia, low visual acuity on the right and unsteady gait. FD was discharged in November 1997 with some right visual field difficulties, improving gait with residual unsteadiness, and persisting communication difficulties, for which he was referred for rehabilitation.

\section{Language skills}

FD presented with good comprehension and spoken output. His speech revealed mild wordfinding difficulties with semantic paraphasias evident in confrontational naming tests and in connected speech. FD also had a severe reading impairment both for comprehension of written text and when reading aloud. FD was asked to complete a comprehensive language assessment and the results are presented below. In particular, we conducted a detailed analysis of FD's reading. Initial assessment revealed FD's prolonged attempts to identify each word with a letter-byletter strategy (e.g., STOP $\rightarrow$ "S.T.E.P. ... stop"; OPEN $\rightarrow$ "O.P.E.N. ... open”). ${ }^{1}$ Although FD was able to recognise a minority of words using this strategy, he would most commonly make letter recognition errors and ultimately fail to identify the target word (e.g, TRACK $\rightarrow$ "T.R.A.Q.D. ... ... no"; service $\rightarrow$ "S.E.R.Y. ... ... no"). Most strikingly, FD would sometimes offer an approximate definition of the target word during his prolonged letter-by-letter attempts (e.g., EXIT $\rightarrow$ "H., no, D.X.I.P. ... notice on a door"; RELIGION $\rightarrow$ "something religious again ... getting better ... F.E.Y.I.R.I.O. ...”).

\section{Letter-by-letter reading}

Patients with pure alexia or letter-by-letter reading demonstrate increasing reading times as a function of letter length. In order to test for this central symptom of letter-by-letter reading, FD was presented with 60 high-frequency words that varied in length (two to five letters-matched for frequency across each length). The use of high-frequency vocabulary was essential given that, with less frequent items, FD's omission rate was too high for collecting sufficient timing data. FD's mean correct reading times and error rates are shown in Figure 2. For these words, FD demonstrated a clear effect of word length on both reading times and accuracy. Reading was slow overall and rose from an average of 11 seconds for two letter words up to 38 seconds for five-letter items. FD was relatively accurate for the shorter items but he made considerably more errors on the longest words.

Patients with pure alexia demonstrate poor reading in the context of preserved writing and

\footnotetext{
1 Target words are denoted in small capitals; letter-by-letter attempts are represented by full capital letters punctuated by full stops; any other comments or spoken responses are shown between inverted commas.
} 


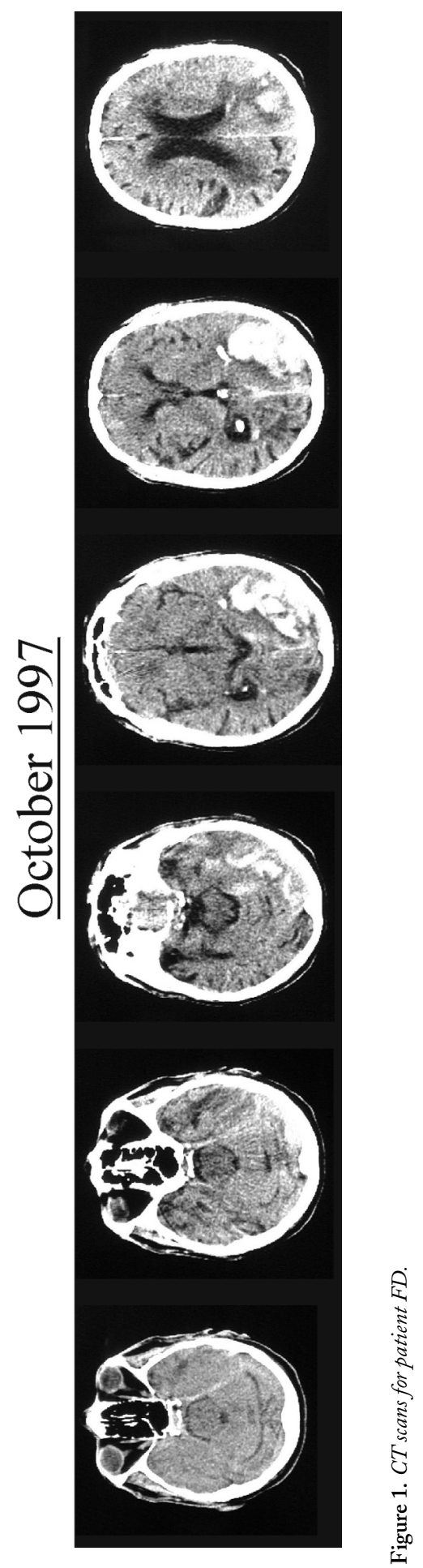

406 COGNITIVE NEUROPSYCHOLOGY, 2004, 21 (2/3/4)

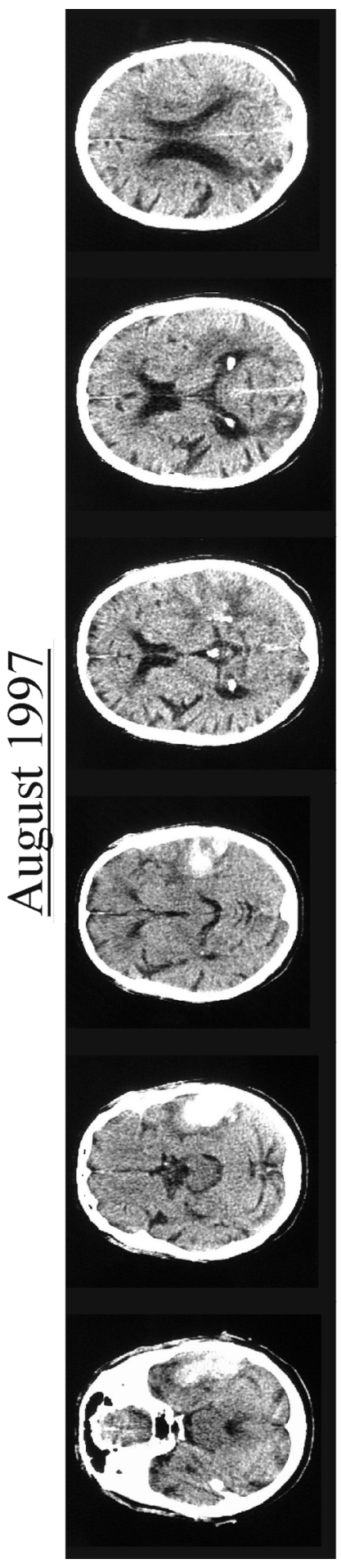

5
0
$\vdots$
0
0
0
0
0

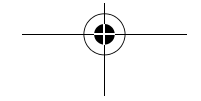




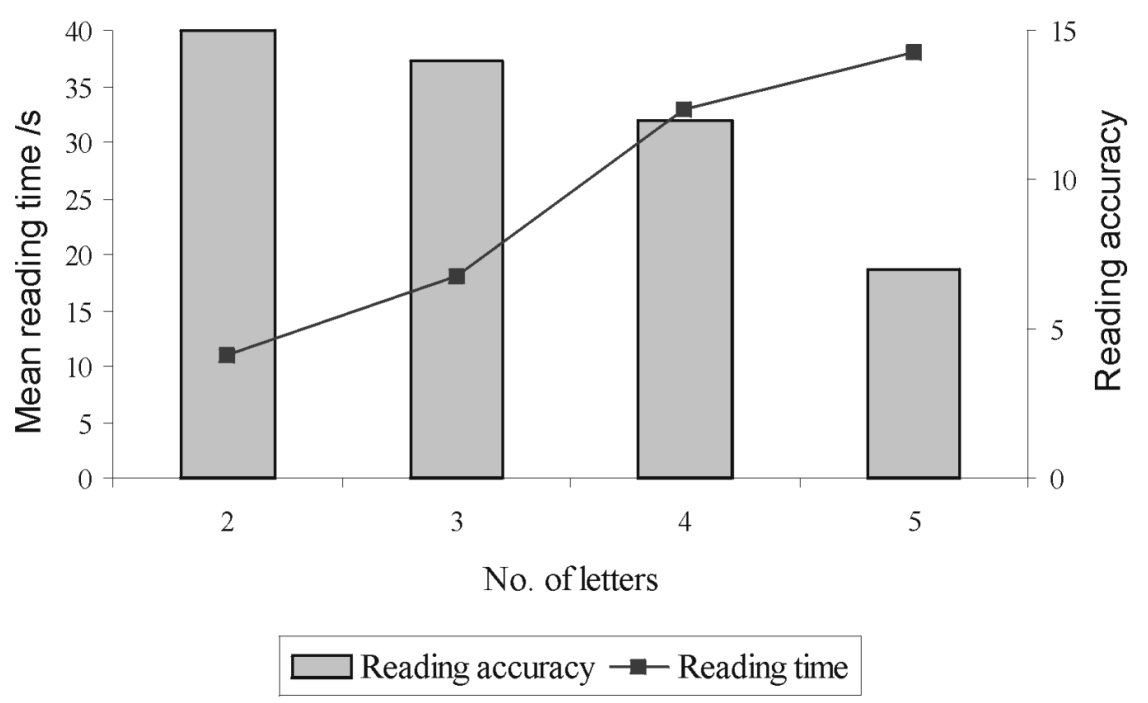

Figure 2. FD's average reading time and error rate as a function of length.

the absence of aphasia. This leads to the striking clinical observation of patients who cannot read their own written output. Both aspects were tested in FD. The more general language assessment is reported below. In order to compare spelling and reading, FD was given both words and nonwords that vary in letter length (tests 39 and 36 from the PALPA battery: Kay, Lesser, \& Coltheart, 1992). For the words, FD was asked to complete four tasks: reading aloud; "reading" or recognition of the words spoken letter-by-letter by the examiner; oral and written spelling to dictation. For the nonwords, only reading and recognition of orally spelled words were compared. FD's reading of the words was poor and accuracy did not vary across length. Performance on the other three tasks was no better, although FD tended to be more accurate for the shorter than longer items. There was, however, a significant difference on the nonwords. FD was only able to read two of the shortest nonwords but was able to construct the correct pronunciation for a larger number of the items when the letters were spoken by the examiner (McNemar, $p=.001)$. It seems likely that FD's poor spelling was due to mild concurrent aphasia (see below).

Table 1. FD's reading and spelling performance as a function of length

\begin{tabular}{lccccc}
\hline & \multicolumn{5}{c}{ Letter length } \\
\cline { 2 - 4 } \multicolumn{1}{c}{ Task } & 3 & 4 & 5 & 6 & Overall \\
\cline { 2 - 4 } & & & & \\
Words (PALPA 39) & $2 / 6$ & $3 / 6$ & $3 / 6$ & $3 / 6$ & $14 / 24$ \\
$\begin{array}{l}\text { Reading } \\
\text { "Reading" of spoken letter strings }\end{array}$ & $6 / 6$ & $5 / 6$ & $3 / 6$ & $3 / 6$ & $17 / 24$ \\
Oral spelling to dictation & $6 / 6$ & $3 / 6$ & $4 / 6$ & $2 / 6$ & $15 / 24$ \\
Writing to dictation & $6 / 6$ & $2 / 6$ & $3 / 6$ & $1 / 6$ & $12 / 24$ \\
Nonwords (PALPA 36) & & & & & \\
Reading & $2 / 6$ & $0 / 6$ & $0 / 6$ & $0 / 6$ & $2 / 24$ \\
"Reading" of spoken letter strings & $6 / 6$ & $2 / 6$ & $3 / 6$ & $2 / 6$ & $13 / 24$ \\
\hline
\end{tabular}




\section{General visual processing}

Table 2 shows FD's results from a range of tests designed to tap letter and number recognition in addition to more general visual perception. Initial reading assessments had found that FD's letter-byletter attempts commonly contained letter recognition errors. The assessments of letter processing demonstrated the same impairment. Although able to complete cross-case letter matching without error, FD's recognition was impaired for single letters and letter sequences whether presented in upper or lower case. Like other patients in the literature (Behrmann et al., 1998b), FD's impaired reading was associated with a more general, visual perceptual deficit. His scores on

Table 2. Assessment of FD's visual perception and recognition

\begin{tabular}{|c|c|c|}
\hline Test & $\begin{array}{l}\text { FD's } \\
\text { score }\end{array}$ & Norms \\
\hline$V O S P$ & & $\begin{array}{r}\text { Normal } \\
\text { cut-off }\end{array}$ \\
\hline Screen & 19 & 15 \\
\hline Incomplete letters & 16 & 16 \\
\hline Silhouettes & $7^{\mathrm{a}}$ & 15 \\
\hline Object decision & $13^{\mathrm{a}}$ & 14 \\
\hline Progressive silhouettes & 15 & 15 \\
\hline Dot counting & 9 & 8 \\
\hline Position discrimination & $14^{\mathrm{a}}$ & 18 \\
\hline Number location & 7 & 7 \\
\hline Cube analysis & $3^{\mathrm{a}}$ & 6 \\
\hline$B O R B$ & & $\begin{array}{c}\text { Normal } \\
\text { range }\end{array}$ \\
\hline Minimal feature match & $24 / 25$ & $18.5-25$ \\
\hline Foreshortened match & $25 / 25$ & $16.7-25$ \\
\hline Object decision (easy) & $22 / 32^{\mathrm{a}}$ & $28-32$ \\
\hline Object decision (hard) & $21 / 32^{\mathrm{a}}$ & $22-30$ \\
\hline Item match & $30 / 32$ & $24-32$ \\
\hline \multicolumn{3}{|l|}{ Letter recognition } \\
\hline Single, upper case letter naming & $15 / 26^{a}$ & - \\
\hline Single, lower case letter naming & $18 / 26^{a}$ & - \\
\hline Naming of lower case letter sequences & $56 / 80^{a}$ & - \\
\hline Naming of upper case letter sequences & $59 / 80^{a}$ & - \\
\hline Cross-case letter matching (PALPA 20) & $26 / 26$ & 26 \\
\hline Number reading & $24 / 30^{a}$ & - \\
\hline
\end{tabular}

a denotes abnormal performance.

VOSP: Visual Object and Space Perception battery; BORB: Birmingham Object Recognition Battery; PALPA: Psycholinguistic Assessments of Language Processing in Aphasia. a number of the subtests from the VOSP (Warrington \& James, 1991) and BORB (Riddoch \& Humphreys, 1992) were abnormal, denoting impaired object recognition and space perception. Although his score on the incomplete letters subtest was within the normal range for accuracy, FD's performance was slow and he often traced the target letter. FD's impaired visual processing also extended to number recognition. In a simple assessment, FD was presented with 30 numbers ranging from two to seven digits in length. His number reading errors contained both digit recognition and syntax errors (e.g., $7456 \rightarrow$ "seven thousand, four hundred and twenty-six; $8372 \rightarrow$ "eight hundred, three seven two").

\section{General language assessment}

FD was given a range of tests designed to assess naming, comprehension, and phonology. The results are summarised in Table 3 . On three standard tests of naming to confrontation (Boston Naming Test, Graded Naming Test, and test 54 from the PALPA battery: Goodglass, Kaplan, \& Weintraub, 1983; McKenna \& Warrington, 1983), FD's scores fell below the normal range. Given the evidence for visuospatial deficits, FD's impaired naming could have been due to poor visual recognition and/or concurrent aphasia. In order to test this further, FD was asked to complete an additional naming task in which items were either presented as spoken definitions or as pictures. This assessment revealed that FD's picture naming was significantly worse than when naming the same items from spoken definitions, suggesting that his poor picture naming was due, in part, to poor visual recognition $(\mathrm{McNemar}$, Exact $p=.02)$. In addition, FD's naming to definition fell slightly below the normal range. Along with the clinical observations of wordfinding difficulties in spontaneous speech (see above), this suggests that FD did have mild, additional, aphasic word-finding difficulties.

FD was asked to complete a number of comprehension assessments. These were selected in order to vary the modality of input and difficulty. On a 100-item word-picture matching test with semantic foils (four foils per trial), FD's performance on 
Table 3. FD's background neuropsychological results

\begin{tabular}{|c|c|c|}
\hline Test & $\begin{array}{l}\text { FD's } \\
\text { score }\end{array}$ & Norms \\
\hline \multicolumn{3}{|l|}{ Naming } \\
\hline Boston Naming Test & $11 / 60^{\mathrm{a}}$ & $42-60$ \\
\hline Graded Naming Test & \multicolumn{2}{|r|}{ S.D. $=4.1$} \\
\hline PALPA 54 Picture Naming & $51 / 60^{\mathrm{a}}$ & - \\
\hline \multicolumn{3}{|l|}{ Naming } \\
\hline From definitions & $44 / 51$ & $49-51$ \\
\hline Pictures & $35 / 51^{a}$ & $50-51$ \\
\hline \multicolumn{3}{|l|}{ Comprehension } \\
\hline \multicolumn{3}{|l|}{100 -item } \\
\hline Written word-picture matching & $42 / 100^{a}$ & $96-100$ \\
\hline Spoken word-picture matching & $79 / 100^{a}$ & $96-100$ \\
\hline \multicolumn{3}{|l|}{ PALPA } \\
\hline Written word-picture matching & $2 / 15^{\mathrm{a}}$ & $35-40$ \\
\hline Spoken word-picture matching & $35 / 40$ & $35-40$ \\
\hline BORB association matching & $25 / 30$ & $21-30$ \\
\hline \multicolumn{3}{|l|}{ Pyramids and Palm Trees Test } \\
\hline Pictures & $42 / 52^{\mathrm{a}}$ & $49-52$ \\
\hline Spoken words & $46 / 52^{*}$ & $49-52$ \\
\hline \multicolumn{3}{|l|}{ Concrete and abstract synonyms } \\
\hline Concrete & $19 / 25$ & $50-75$ th \%ile \\
\hline Abstract & $18 / 25$ & $50-75$ th \%ile \\
\hline PALPA auditory synonyms & $55 / 60$ & - \\
\hline ADA auditory synonyms & $148 / 160^{a}$ & $152-160$ \\
\hline \multicolumn{3}{|l|}{ Phonology } \\
\hline $\begin{array}{l}\text { ADA word and nonword repetition } \\
\text { PALPA }\end{array}$ & $79 / 80$ & $52-80$ \\
\hline Syllable length word repetition & $24 / 24$ & - \\
\hline $\begin{array}{l}\text { Syllable length nonword } \\
\text { repetition }\end{array}$ & $29 / 30$ & - \\
\hline $\begin{array}{l}\text { Morphologically complex word } \\
\text { repetition }\end{array}$ & $87 / 90$ & - \\
\hline Syllable counting & $13 / 24^{a}$ & $22-24$ \\
\hline Initial consonant deletion & $18 / 24^{a}$ & $21-23$ \\
\hline Rhyme judgement & $20 / 24$ & $20-24$ \\
\hline
\end{tabular}

${ }^{a}$ Denotes abnormal score.

the spoken and written versions fell below the normal range and the score for written wordpicture matching was significantly worse than for the spoken version of the same test $(\mathrm{McNemar}$, Exact, $p<.001)$. This is unsurprising given that in this condition both the word and pictures require visual recognition. Indeed, on the PALPA version of the same test, FD's performance was so bad that the assessment had to be discontinued after 15 items. On the other hand, FD's score on the spoken version fell into the normal range published with this test. FD's comprehension was also assessed using the semantic association tasks from the BORB in addition to the picture and spoken word versions of the Pyramids and Palm Trees test (PPT: Howard \& Patterson, 1992). For the BORB association test, FD's score fell into the normal range while on the spoken and picture versions of the PPT his performance was mildly abnormal. Given that we had already found evidence for a generalised visual perceptual deficit that impacted on FD's picture naming ability (see above), we also administered three comprehension tests that avoided the visual modality completely. The concrete and abstract synonyms test (Warrington, McKenna, \& Orpwood, 1998) contains a series of psychometrically graded word triads that are spoken by the examiner. On both the concrete and abstract items, FD's scores placed him in the normal range. Likewise, on the PALPA auditory synonyms his performance was good and on the ADA version (Franklin, Turner, \& Ellis, 1992) his score fell only a few points below the normal range for undergraduates published with this test.

Given FD's poor spelling and aphasic wordfinding difficulties, we also asked him to complete a number of tests of phonology. On a series of word and nonword repetition tasks that vary morphological complexity and syllable length, FD's scores were excellent. Evidence for a slight phonological impairment was highlighted, however, in two of three phonological awareness tasks that require deliberate manipulation of word sound (syllable counting and initial consonant deletion).

In summary, FD's very poor reading was accompanied by a general visuospatial deficit in addition to a very mild impairment of phonology plus some aphasic word-finding difficulties (which may have been due to the underlying phonological impairment itself). FD's excellent performance on the tests of spoken word comprehension suggest that there is little or no evidence for a semantic impairment; his poor comprehension of written words and pictures is entirely consistent with his underlying alexia and visuospatial deficit. 


\section{FD's Saffran effect}

One of the most striking aspects of FD's reading attempts was his ability to indicate the meaning of a word without giving the actual identity of the target itself. Like the patients described by Saffran and Coslett (1998), this suggests that FD was still able to access the partial meaning of written words. In order to test this more formally, FD was asked to complete three two-alternative forced-choice semantic categorisation tasks. For each assessment, a fixation cross was followed by the brief $(250 \mathrm{~ms})$ presentation of the target word. FD was encouraged to indicate the correct category (food vs. nonfood; animal vs. nonanimal, male vs. female names) even though he was unable to see the word clearly enough to report its identity. Where FD was uncertain, he was asked to guess. FD's performance is summarised in Table 4. Given that the tests were identical to those administered by Saffran and Coslett, FD's scores are given alongside their patients' for direct comparison.

Table 4 shows that FD did exhibit the Saffran effect: Despite being unable to give the identity of any of these items, his categorisation performance was significantly above chance in all three tests and was comparable in magnitude to the effect found by Saffran and Coslett (1998). Although the combination of above-chance categorisation without overt word recognition is very striking, it should be noted that the scores of FD and all the other patients fell into the mid range. As far as we are aware, no patient has ever demonstrated performance close to ceiling without overt recognition. Likewise, when indicating the meaning of a written word during his letter-by-letter attempts, FD never gave the exact meaning of the target word and he only did this for a subset of the items.
The graded nature of FD's performance was investigated more thoroughly in a second series of brief presentation experiments.

\section{What is the basis of the Saffran effect?}

\section{Manipulating FD's accuracy}

In the Introduction we laid out two possible explanations for the Saffran effect. The first assumes that the apparent dissociation in brief presentation experiments between good categorisation/lexical decision performance and no overt word recognition reflects two separate reading systems. The alternative explanation suggests that whole-word recognition is still supported by a single reading system, albeit with severely impaired visual input, supplemented by a letter-by-letter strategy. The brief presentation technique prevents any use of letter-by-letter reading and the remaining ability of the impaired, premorbid reading system is laid bare. These two explanations were tested in two investigations: One utilised a specific therapy intervention that discouraged the letterby-letter approach almost entirely, meaning that FD's reading could be explored without needing the brief presentation method (see below). In addition, prior to therapy intervention, we used a series of further brief presentation tasks to explore the underlying nature of FD's reading.

If the Saffran effect reflects the nature of the single, premorbid reading system, then it should be possible to manipulate the patients' accuracy by varying factors that are known to influence normal and impaired reading performance. In the limit, with the most favourable items, this single reading system might be able to recognise words overtlythat is to say, how much of a word's meaning is

Table 4. FD's performance on Saffran's $2 A F C$ semantic categorisation tasks

\begin{tabular}{|c|c|c|c|c|c|c|c|}
\hline \multirow[b]{2}{*}{ Categorisation task } & \multirow[b]{2}{*}{$N$} & \multicolumn{4}{|c|}{ Saffran and Coslett (1997) patients } & \multicolumn{2}{|c|}{$F D$} \\
\hline & & $J G$ & $T L$ & $J L$ & $A F$ & Accuracy & Binomial, $p$ \\
\hline Food/Non-food & 75 & $80 \%$ & $67 \%$ & $79 \%$ & $76 \%$ & $61 \%$ & .03 \\
\hline Animal/Non-animal & 75 & $75 \%$ & $69 \%$ & $85 \%$ & $71 \%$ & $71 \%$ & $<.001$ \\
\hline Male/Female names & 100 & $75 \%$ & $70 \%$ & $71 \%$ & $80 \%$ & $72 \%$ & $<.001$ \\
\hline
\end{tabular}


activated should be a matter of degree rather than the absolute, qualitative difference implied by the two-systems theory. We carried out, therefore, a second series of brief presentation experiments in which the nature of the words and of the forcedchoice were manipulated. The method and presentation times were unchanged. The results are summarised in Table $5 \mathrm{a}$ for the semantic categorisation tasks and in Table $5 \mathrm{~b}$ for the lexical decision tests.

Normal and impaired word recognition is influenced by a number of factors including word frequency/familiarity and imageability (Behrmann et al., 1998b). To investigate the role of frequency/ familiarity in FD, we utilised the fact that religious words were very familiar to him. In the first experiment, we selected 20 Christian terms and paired them with 20 local place names, which were all highly familiar. FD was required to indicate whether the word was either a religious term or a place name. Although not perfect, FD's score of $79 \%$ was the highest of all of the categorisation experiments conducted. Most importantly, with these extremely familiar words, FD was able to recognise six of them even with a $250 \mathrm{~ms}$ presentation, suggesting that in these most favourable conditions, FD's reading system was able to recognise words overtly. In order to test our assumption that it was the familiarity of the words that was critical, we repeated the experiment but also included 40 relatively unfamiliar religious words (non-Christian) and place names (towns in southern England). As can be seen in Table 5a, FD's score on the familiar items was almost unchanged but his performance on the unfamiliar terms was significantly worse, $\chi^{2}=3.81, p=.05$, and no better than chance.

The third set of categorisation experiments tested our observation that patients who demonstrate the Saffran effect only activate a partial

Table 5. Manipulation of FD's (a) categorisation accuracy and (b) lexical decision accuracy

\begin{tabular}{|c|c|c|c|}
\hline Task & $N$ & Accuracy & Binomial, $p$ \\
\hline \multicolumn{4}{|c|}{ (a) Categorisation accuracy } \\
\hline Religious terms vs. Local place names & $34^{\mathrm{a}}$ & $79 \%$ & $<.001$ \\
\hline Religious terms vs. Place names & 80 & $69 \%$ & $<.001$ \\
\hline High familiarity & 40 & $78 \%$ & $<.001$ \\
\hline Low familiarity & 40 & $60 \%$ & n.s. \\
\hline \multicolumn{4}{|l|}{$4 \mathrm{AFC}$ vs. $2 \mathrm{AFC}$} \\
\hline Birds vs. Animals vs. Tools vs. Vehicles & 80 & $29 \%$ & n.s. \\
\hline Animals vs. Artefacts & 80 & $64 \%$ & .01 \\
\hline Birds vs. Animals & 40 & $65 \%$ & .04 \\
\hline Tools vs. Vehicles & 40 & $65 \%$ & .04 \\
\hline Native/Foreign & 40 & $68 \%$ & .02 \\
\hline
\end{tabular}

(b) Lexical decision accuracy

\begin{tabular}{lrcc}
\hline Lexical decision (PALPA 24) with & & & \\
Illegal nonwords & 60 & $88 \%$ & $<.001$ \\
Legal nonwords & 60 & $68 \%$ & .003 \\
Imageability by Frequency (PALPA 25) & 120 & $64 \%$ & .001 \\
High Imageability/High Frequency & 15 & $93 \%$ & $<.001$ \\
Low Imageability/High Frequency & 15 & $47 \%$ & n.s. \\
High Imageability/Low Frequency & 15 & $53 \%$ & n.s. \\
Low Imageability/Low Frequency & 15 & $60 \%$ & n.s. \\
Nonwords & 60 & $65 \%$ & .01 \\
\hline
\end{tabular}

a The test contains 40 items but FD was able to recognise 6 words even with a 250 ms brief presentation. 
semantic representation that is commensurate with the degree of remaining activation throughout the whole of the reading system. Two types of semantic specificity were tested. First, we manipulated the number of alternatives on offer in the categorisation experiment (4AFC: birds vs. animals vs. tools vs. vehicles; or 2AFC: animals vs. artefacts, etc.). Under our working hypothesis it might be the case that performance would drop in line with the number of alternatives (as Shallice \& Saffran, 1986, had found). Second, we manipulated the semantic differentiation required by the categorisation. FD was asked to differentiate at the level of domain (animals vs. artefacts), or between categories (birds vs. animals or tools vs. vehicles) or on the basis of more specific information (native or foreign creatures). As can be seen in Table $5 \mathrm{a}$, the number of alternatives, but not the level of semantic differentiation, influenced FD's accuracy.

The results from the categorisation experiments are consistent with the notion that FD's reading performance reflects the partial remaining activation within a single, damaged reading system. The degree of activation varies in line with the frequency/familiarity of the words. In addition the remaining activation is sufficient to push twoalternative judgements above chance levels but insufficient to support categorisations with more choices. Saffran and Coslett (1998) also explored their patients' reading performance using lexical decision under brief presentation. We included, therefore, two lexical decision experiments that explored related word characteristics. The results are shown in Table $5 b$.

Assuming that the Saffran effect reflects partial activation within the remaining single reading system, lexical decision-like categorisationshould vary according to word characteristics like frequency and imageability. In addition, partial activation may only be able to support relatively easy decisions. The first experiment was designed to vary the difficulty of the lexical decision (in a similar way to Shallice \& Saffran, 1986). Items were taken from the PALPA lexical decision test with illegal nonwords (e.g., CLIP vs. AEMF) and presented under the same brief presentation conditions. In addition, the experiment was repeated but the illegal items were replaced by legal nonwords derived from the real words (e.g., CLIP vs. CLEP). FD performed above chance on both variants of the experiment but his accuracy was significantly enhanced when he was required to distinguish between words and illegal nonwords, $\chi^{2}=7.07$, $p=.008$.

The previous categorisation tasks found a clear effect of frequency on performance. The second experiment tested whether this was also true for lexical decision while also varying word imageability. Studies of other milder letter-by-letter readers have found evidence for frequency and imageability in reading times (Behrmann et al., 1998b). Items were selected from PALPA test number 25, which orthogonally varies both frequency and imageability and pairs each word with a legal nonword. Overall, FD's lexical decision accuracy (64\%) was very similar to the first lexical decision experiment that used legal nonwords (68\%). His performance for the words varied, however, in line with the lexical variables. Specifically, FD's recognition of words was only significantly above chance for concrete, high frequency items.

\section{Is there really a dissociation between word identification and "implicit" recognition?}

The results from the brief presentation lexical decision and categorisation experiments produced very similar results. Overall, FD's accuracy was influenced by the frequency and imageability of the words and by the difficulty of the decision. This is consistent with the proposal that the Saffran effect is underpinned by the remaining activation of the damaged reading system (Behrmann et al., 1998b; Feinberg et al., 1994; Shallice \& Saffran, 1986). This reduced activation will be sufficient to resolve simple discriminations and just like any other normal or impaired system, activation is graded by characteristics such as frequency and imageability. In the limit, with the most favourable items, the remaining activation is sufficient to support nearnormal processing-in this case, relatively quick whole-word recognition. These results are consistent with a single system account of the Saffran effect in which there are graded rather than absolute differences in processing. Setting aside 
IMPLICIT RECOGNITION IN PURE ALEXIA

Table 6. FD's performance on the $2 A F C$ word recognition vs. categorisation task

\begin{tabular}{lcccc}
\hline & \multicolumn{3}{c}{ Foil type in $2 A F C$ word recognition task } & Semantic \\
\cline { 2 - 4 } Target & Shared onset & Shared end & Semantic & categorisation \\
\hline e.g., duck & dusk & tuck & swan & Living vs. \\
e.g., bath & bash & path & shower & nonliving \\
Accuracy $(N=40)$ & $70 \%$ & $90 \%$ & $90 \%$ & $45 \%$ \\
Binomial, $p$ & .01 & $<.001$ & $<.001$ & n.s. \\
\hline
\end{tabular}

neurological issues (to which we return in the General Discussion), the two system account is based on the observation of a dissociation between poor word identification but good categorisation. FD's results show that categorisation performance varies in a predictable way and occasionally word identification is possible even under brief presentation. One could wonder, therefore, whether there really is a dissociation between word identification and categorisation in these patients-particularly as the two tasks are not equivalent. ${ }^{2}$ Word identification is measured simply in terms of reading aloud-i.e., an unconstrained response by the patient. Categorisation (either semantic or lexical), on the other hand, is measured most often by a 2AFC task. It is easy to imagine that a reduced amount of residual activation in the reading system would be sufficient to achieve above-chance accuracy in the 2AFC task (albeit not perfect performance) but that this would be insufficient to derive any overt reading response. We, like Shallice and Saffran (1986), have already demonstrated that FD's accuracy fell significantly in a 4AFC task, so if one extrapolates this to the number of words in an adult's reading vocabulary then it is unsurprising that the system cannot ascertain exactly which word is present.

Our last brief presentation experiment was designed to equate the nature of word identification and categorisation. Forty monosyllabic words were presented in a series of $2 \mathrm{AFC}$ conditions that measured either word identification or semantic categorisation (living vs. nonliving). Three types of foil were included in the 2AFC identification tasks. A foil was derived from each target item by changing either its end (i.e., shared onset and vowel: DUCK vs. DUSK) or beginning (i.e., shared vowel and offset: DUCK vs. TUCK). We also included a semantically-related foil (e.g., DUCK vs. SWAN). The last experimental condition required a living vs. nonliving semantic categorisation. The conditions were counterbalanced across four testing sessions. For each trial, the single target word was presented on the screen for $250 \mathrm{~ms}$, preceded by a fixation cross, and the examiner offered FD either two possible words or categories to choose from.

FD's results across the four conditions are shown in Table 6. A number of important features were highlighted by this experiment. The left-toright position of the differing letters was important. Although performance in all three versions of the 2AFC identification experiment was significantly above chance, FD's accuracy was significantly better if the words differed at the beginning rather than at the end. His performance was also very good for the semantic foils, which typically shared few if any letters in common, although it is striking that FD accepted the semantic foil in 4/40 trials (for example, FD accepted "shower" for BATH). In this experiment, his semantic categorisation was very poor (at chance) but his $2 \mathrm{AFC}$ word identification in the shared onset condition was equivalent to the accuracy he typically achieved on most $2 \mathrm{AFC}$ semantic categorisation experiments (around 70\%). In conclusion, once the

\footnotetext{
${ }^{2}$ We are indebted to Karalyn Patterson for pointing this fact out to us and for the experimental solution.
} 
nature of the two tasks is made equivalent, there is no evidence to suggest that categorisation is any better than word identification. Based on these results, there is no evidence for a dissociation between the two tasks and thus little motivation for a two systems model. The results from this experiment, taken with those reported above, are consistent with a single system hypothesis.

As noted before, Saffran and Coslett (1998) have argued that above-chance semantic categorisation in these brief presentation experiments is highly dependent on the strategy adopted by the patient. Patients have to be encouraged away from using their letter-by-letter strategy to identify the target word specifically. One could wonder, therefore, whether the $2 \mathrm{AFC}$ word identification task used in this experiment discouraged or even inhibited (Landis et al., 1980) the implicit, righthemisphere reading system leading to poor performance on the semantic categorisation task. While this strategy argument may explain FD's poor semantic categorisation in this specific experiment, the important observation is that his word identification skills, when measured using a $2 \mathrm{AFC}$ procedure, are exactly commensurate with his categorisation performance on all the other $2 \mathrm{AFC}$ tasks reported above, none of which emphasised word identity.

\section{Removing the letter-by-letter strategy: $F D$ - the deep dyslexic}

The last investigation of FD's reading assessed the impact of a specific therapy intervention. The details of the therapy and its outcome are reported elsewhere (Sage, Hesketh, \& Lambon Ralph, 2003) but the key elements are repeated here. It is the particular effect it had on FD's reading that is critical to the present study. The therapy study was split into three phases. Initially, FD was given a baseline assessment for three sets of words, comprising both experimental words (matched across sets for frequency and length) as well as some personally relevant vocabulary. In the second phase, FD was given daily practice on one set of words using an errorless learning approach (Fillingham, Hodgson, Sage, \& Lambon Ralph, 2003; Wilson \& Evans, 1996) to reinforce wholeword recognition. Specifically, FD was shown each word in turn but to prevent errors, he was given the correct pronunciation by the therapist and he then repeated it five times. This therapy was practiced daily for several weeks and FD was then reassessed

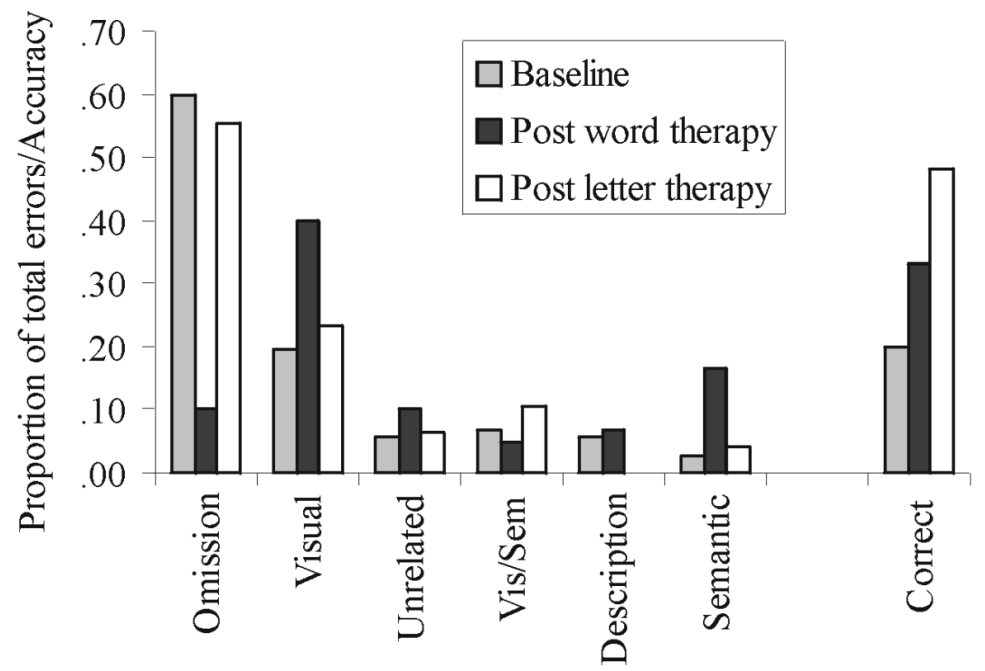

Error type

Figure 3. Influence of therapy type on FD's word reading errors. 
again on all three reading lists. In the final phase, the errorless learning approach was retained but therapy moved from the word to the letter level. This time, the therapist concentrated on individual letters and later, letters within words, again using repetition as the errorless method. After another few weeks of daily practice, FD was assessed again on all three word sets.

The right-hand side of Figure 3 shows the total accuracy for the three word sets at baseline and after each round of therapy. In each case, there was a significant increase in accuracy for the set of therapy items with no significant generalisation to the control words. For the purposes of this study, the two therapies had a dramatic effect on both FD's reading strategy and the distribution of his reading errors. Prior to therapy, FD tried to use an overt letter-by-letter strategy on 68/90 words. Following whole-word therapy he almost completely gave up on this reading strategy, attempting letter-by-letter reading for only $6 / 90$ words and showed a correspondingly (relatively) quicker reading time. Although we did not formally reassess reading times for words of varying lengths, the change in FD's overt reading behaviour was so pronounced that had he presented in this way, he probably would not have been considered to be a letter-by-letter reader. Somewhat surprisingly, although we had expected the letter-based therapy to encourage the return of his letter-by-letter reading, there was no change in FD's reading behaviour after the second therapy. Somewhat serendipitously, FD had almost completely given up on the (rather ineffective) letter-by-letter strategy. This is important for two reasons: First, it reinforces the notion that letter-by-letter reading is a strategy that can be deliberately adopted or discarded (Coslett et al., 1993). Second, and most critically for this study, it meant that FD's reading now reflected his underlying, impaired reading system without compensation by the letter-by-letter approach. In such circumstances, the use of brief presentation to inhibit this strategy was no longer necessary.

In addition to changing his reading style, the two therapy interventions had a dramatic effect on the distribution of FD's reading errors. This is shown in the remainder of Figure 3. As the distribution was very similar for each word set, the error data was combined. At each testing round, FD made a mixture of omissions; visual, semantic, visual-semantic, and unrelated reading errors, together with a handful of responses that gave an indication of the words' meaning (denoted here as description errors). Following each therapy, there was a significant change in the distribution of errors although the distribution following the letter therapy was not significantly different to baseline: baseline vs. post whole-word therapy, $\chi^{2}(5)=34.7, p<.001$; post whole-word therapy vs. post letter-based therapy, $\chi^{2}(5)=27.9, p<.001$; base-line vs. post letter-based therapy, $\chi^{2}(5)=$ 3.60, $p=.61$. The whole-word therapy changed the rate of three types of error (as a proportion of total errors): omissions dropped from $60 \%$ to $10 \%$; visual errors jumped from $20 \%$ to $40 \%$; while, most strikingly, the rate of pure semantic errors climbed dramatically from $3 \%$ to $17 \%$ (e.g., TRUTH $\rightarrow$ "faith, no ... preach?"; ASPIRIN $\rightarrow$ "hospital"). In effect, FD had changed from a poor letter-byletter reader into a deep dyslexic. Although the subsequent, letter-based therapy did not reinvigorate his letter-by-letter reading, it did return his error pattern back to the same as at baseline, with omission errors predominating. His reading, at this stage, would best be described as a form of visual dyslexia (Lambon Ralph \& Ellis, 1997).

In order to check the apparent emergence of deep dyslexia after the whole-word therapy, we asked FD to complete three PALPA reading assessments prior to commencing the letter-based therapy. These were selected to test for the symptoms of deep dyslexia (semantic errors, imageability effect, part-of-speech-effect, and abolished nonword reading: Coltheart, Patterson, \& Marshall, 1980). In an assessment that varies imageability and frequency (PALPA no. 31), FD only managed to read 11/80 items correctly (with no letter-by-letter attempts). He demonstrated a small but significant imageability effect (high imageability $-10 / 40$ vs. low imageability $1 / 40$ : $\left.\chi^{2}=8.54, p=.003\right)$. On this set of items, omission errors were the most frequent type (51\%), with $13 \%$ semantic errors (e.g., GRAVY $\rightarrow$ "stew"; 
ONION $\rightarrow$ "apple"), $22 \%$ visually related, and $14 \%$ unrelated real word errors. FD's reading of words that vary their part of speech (nouns, adjectives, verbs, and functors: PALPA test no. 24) was very poor. He managed to read only $2 / 10$ nouns and $1 / 10$ adjectives, making a variety of errors including semantic paralexias (e.g., HANG $\rightarrow$ “door", GENTLE $\rightarrow$ "stroke"). FD was also unable to read any of the short nonwords included in PALPA test no. 24 (though it should be noted that his nonword reading was found to be very poor at initial presentation). In conclusion, FD demonstrated all of the symptoms of deep dyslexia with the exception of a part-of-speech effect-though his reading on this test was close to floor. FD's emergent deep dyslexia is, of course, exactly what one would expect from the two-system hypothesis (Buxbaum \& Coslett, 1996; Saffran \& Coslett, 1998). Right hemisphere reading is assumed to have overt reading skills that are limited to concrete, real words and might be associated with the production of semantic paralexia (as per the right hemisphere hypothesis for deep dyslexia itself: Coltheart, 2000). This outcome is also consistent, however, with the single-system hypothesis: Damage to computationally-implemented models containing a single reading system produces deep dyslexia (Plaut \& Shallice, 1993).

\section{Why does the Saffran effect vary across letter-by-letter readers?}

One major unresolved issue in the literature regarding the Saffran effect is why only a proportion of patients with letter-by-letter reading or pure alexia demonstrate the effect (Coltheart, 1998). Even with extensive testing across many patients, other studies have found little or no evidence for above-chance categorisation in brief presentation experiments (e.g., Patterson \& Kay, 1982). One possibility is that patients who exhibit the Saffran effect not only have letter-by-letter reading but also some other critical impairment. The background testing revealed that FD was not a pure alexic in that his letter-by-letter reading was accompanied by some mild aphasic symptoms (word-finding difficulties and an impaired ability to manipulate phonology) along with some spelling problems. One could imagine, therefore, that these subtle language deficits might interfere with the letter-by-letter strategy (which requires letters to be remembered and then blended-i.e., it relies on some phonological skills) and thus reading falls back on the damaged whole-word reading system. This possibility does not seem to hold, however, for Coslett and Saffran's patients (1989). All patients were given the Boston Diagnostic Aphasia Examination, on which their performance (i) was entirely normal (patients TL and $\mathrm{AF}$ ), or (ii) revealed very subtle degrees of anomia (patient JG), or (iii) slight spelling problems (patient JC).

The second possibility is that the implicit categorisation experiments need to be administered in the correct fashion. Saffran and Coslett (1998) argued that not only brief presentation but also gentle cajoling of the patients was required for them to dispense with their letter-by-letter reading, which otherwise blocks the output of the (right hemisphere) covert reading system. This methodological explanation may be true for certain patients who can switch between efficient letterby-letter reading and responses based on wholeword reading (patient JWC: Coslett et al., 1993) but it seems unlikely for the majority of cases. Indeed, letter-by-letter reading and the activation of higher-order word and semantic representations are not mutually exclusive. As noted in the Introduction, a number of studies have shown evidence for lexical and semantic effects on the reading times of letter-by-letter readers and the symptoms of pure and deep dyslexia can co-occur (Behrmann et al., 1998b; Buxbaum \& Coslett, 1996). Furthermore, the dramatic change in FD's reading style following whole-word therapy suggests that it is possible for some patients to dispense with the letter-by-letter reading strategy altogether. Rather than revealing a simple covert reading system, FD was still able to produce overt responses, albeit of the impoverished type expected for a patient with deep dyslexia.

The third explanation relates to patient severity. Behrmann and colleagues have argued that there may be an inverted U-shaped function that relates 
Reading times for the patients exhibiting the Saffran effect

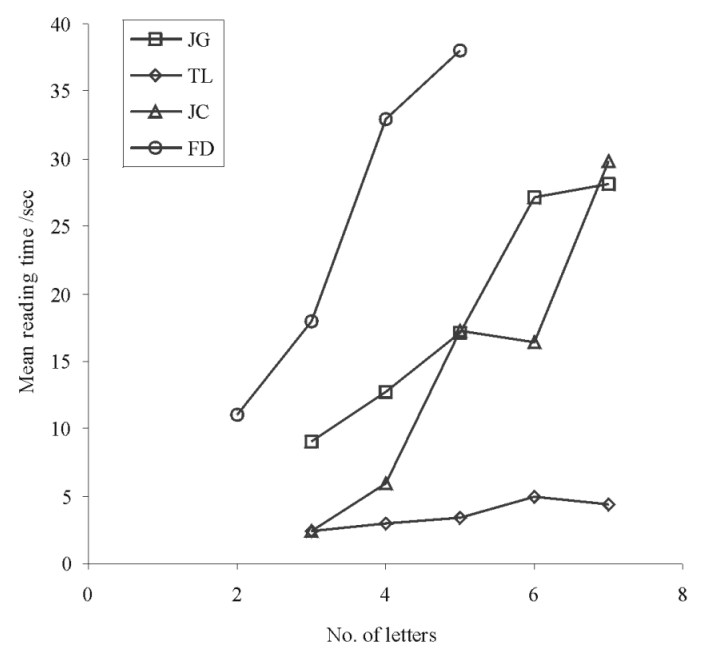

Error rate for the patients exhibiting the Saffran effect

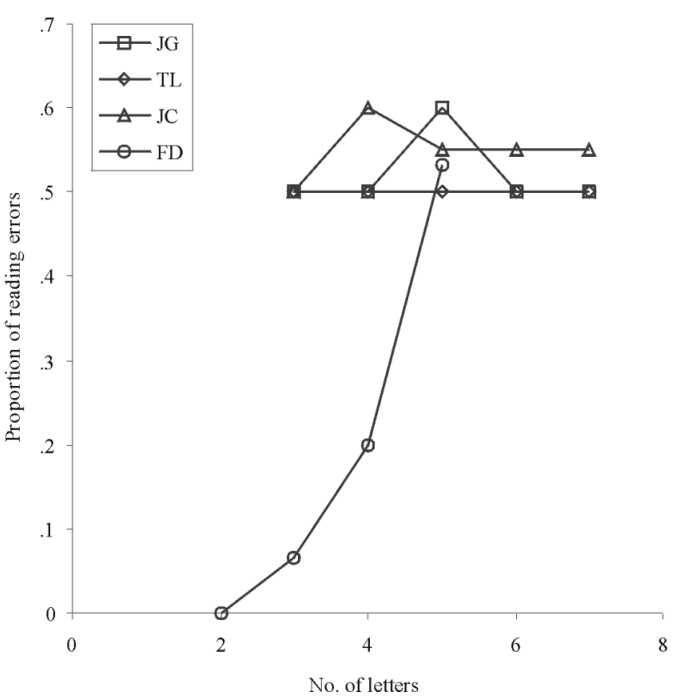

Reading times for the patients not exhibiting the Saffran effect

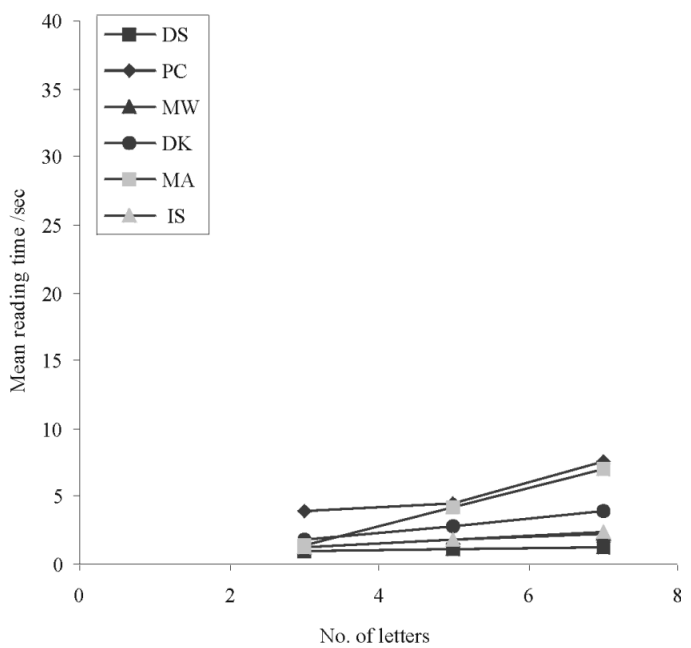

Error rate for the patients not exhibiting the Saffran effect

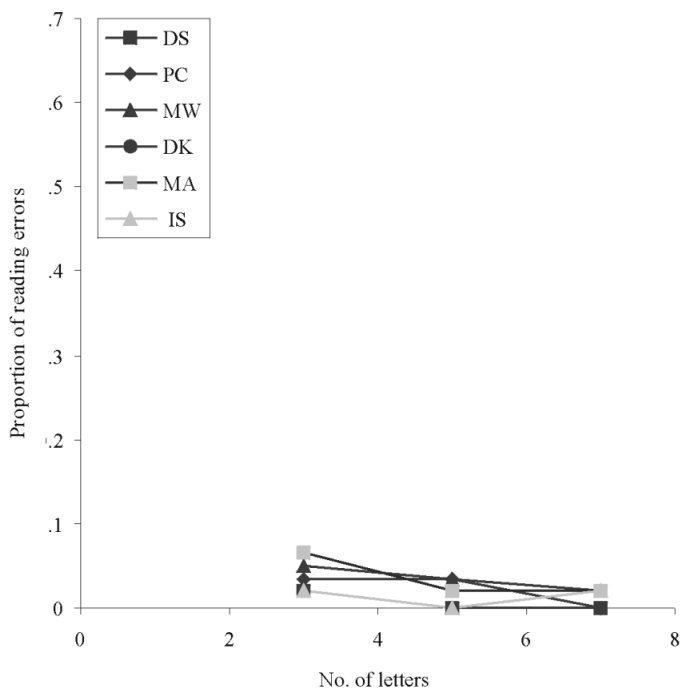

Figure 4. Comparison of reading times and error rates for patients with and without the Saffran effect.

severity and the size of lexical-semantic effects in letter-by-letter readers (Behrmann et al., 1998b). In their case series, Behrmann et al. found correlations between the slope of the word length effect (a proxy for the severity of the reading impairment) and the size of the frequency and imageability effects. The question remains, however, as to whether this explanation can be extended from the influences found on reading times in Behrmann's pure alexics to the Saffran effect exhibited by some patients-which is demonstrated in accuracy rather than response time data. There are some 
hints in the literature that "preserved" reading consistent with the Saffran effect appears at a certain stage during recovery (Landis et al., 1980; Saffran \& Coslett, 1998). Initially patients can have extremely poor or non-existent reading (global alexia), followed by partial recognition and finally, reading via letter-by-letter strategy takes over once sufficient recovery has taken place.

The extension of the severity hypothesis to the Saffran effect would be tested best in a case-series design in which the reading behaviour of a set of patients who vary in reading severity could be compared directly on the same set of materials. In a proxy to such data, we combined the reading times and accuracy data for the Saffran and Coslett (1998) patients together with FD-all of whom demonstrate the Saffran effect-and compared this against similar data for a group of patients who do not exhibit the Saffran effect (Behrmann, personal communication). ${ }^{3}$ Although these two groups of patient were tested on different materials, the resultant data (see Figure 4) reveal a striking difference. The reading times for the patients who do exhibit the Saffran effect are approximately 10 times slower than the pure alexics who do not show the effect. The exception to this pattern is patient TL (Coslett \& Saffran, 1989a), for whom the word length function falls within the same range of quicker reading times. If error rates are also considered, however, then it is clear that the reading accuracy of the Saffran effect patients is considerably worse than the pure alexics without the Saffran effect (who are, in general, very accurate). It would appear that while some of the Saffran effect patients are both slow and errorful, other cases such as TL and FD adopt a different speed-accuracy trade-off. TL's relatively quick reading times came at the cost of poor accuracy while, at least for short words, FD's good accuracy was countered by excessively slow reading times. Furthermore, after the errorless learning therapy, FD's speed-accuracy trade-off actually reversed such that his much quicker reading times came at the cost of many more commission errors (Sage et al., 2003). Taking reading times and error rates together, these comparative results suggest that reading severity is the key factor that underpins the presence or absence of the Saffran effect.

It might also be possible to extend the severity hypothesis to account for the reading data of two optic aphasics reported by Coslett and Saffran (1989b; Saffran \& Coslett, 1998). These patients were completely unable to name letters or words but still exhibited lexical-semantic effects in lexical decision and sorting tasks. These patients might be even further along the severity continuum such that the whole-word reading system is only activated to a minimal extent - too little to support any overt reading ability but sufficient to sustain limited ability in forced-choice procedures such as lexical decision and sorting.

\section{GENERAL DISCUSSION}

This study adds another case to the very small number of patients reported in the literature who exhibit the Saffran effect (Feinberg et al., 1994; Saffran \& Coslett, 1998; Shallice \& Saffran, 1986). FD demonstrated spontaneous, partial access to word meaning during letter-by-letter reading attempts as well as in brief presentation, categorisation experiments. In both situations, FD activated this partial knowledge without overt recognition of the target words. By combining data from this and two other studies, we were able to investigate why only a proportion of pure alexics exhibit the Saffran effect. This comparison revealed that the patients who do demonstrate the effect are considerably slower and less accurate readers. This is consistent, therefore, with the argument that the severity of the patients' impairment is key (Behrmann et al., 1998b).

Two alternative explanations for the Saffran effect were tested in a series of experiments and through the impact of whole-word and letterbased therapies on FD's reading. In their seminal report, Shallice and Saffran (1986) proposed two

${ }^{3}$ We are grateful to Marlene Behrmann for sharing her data with us. 
theories for this effect. The first was based on the notion that the dissociation between implicit whole-word recognition and explicit, letter-byletter based reading necessitates two separate reading systems underpinned by neural substrates in the left and right hemispheres (Saffran \& Coslett, 1998). The second theory assumes that the patients' behaviour reflects reduced or impaired input to the same single, whole-word reading system that supports normal word recognition, in addition to the deliberate, compensatory strategy of letter-by-letter reading (Behrmann et al., 1998b). Under this alternative hypothesis, the patients' above-chance performance in the brief presentation experiments simply reflects partial, cascading activation within the single, premorbid reading system (Behrmann et al., 1998b; Feinberg et al., 1994).

FD's results strongly support the latter hypothesis. FD's reading behaviour was characterised by partial activation of higher-order word representations, accuracy was graded by word variables known to influence the normal reading system, and, most importantly, once the characteristics of the tasks were equated, there was no evidence for a dissociation between word categorisation and identification-which was, perhaps, the primary motivation for positing two whole-word reading systems. In addition, the whole-word therapy encouraged FD to abandon, almost completely, the letter-by-letter strategy. Without this compensatory technique, FD's reading (a form of either deep or visual dyslexia) was consistent with a partially activated, single, whole-word reading system that produces overt reading responses. These results seem to weaken, or perhaps remove, the need for two whole-word reading systems.

The two systems theory was motivated not only by cognitive but also by neurological factors (Coslett \& Monsul, 1994; Saffran \& Coslett, 1998). While it is possible to question the nature of the behavioural data, we have said nothing specifi- cally about the role of the right and left hemispheres. It is well established that pure alexia is associated with lesions in the left occipitotemporal region (Damasio \& Damasio, 1983). Although FD had suffered from a series of vascular events, it was only after a left posterior cerebral artery stroke that he presented with severe letter-by-letter reading. There is also the intriguing fact that once his letter-by-letter reading was abandoned, FD turned into a deep dyslexic, which would be predicted by the right hemisphere hypothesis of deep dyslexia (Buxbaum \& Coslett, 1996; Coltheart, 1981; Coslett \& Saffran, 1989). ${ }^{4}$ In addition, Coslett and Monsul demonstrated that transcranial magnetic stimulation (TMS) disrupted the reading of patient JG when it was applied over the right but not the left parietal region. While we cannot draw any firm conclusions about the role of the left hemisphere from a failure to disrupt JG's reading, some kind of role for the right hemisphere is indisputable.

While the neurology of the Saffran-effect patients (including FD) and the TMS results from patient JG are consistent with the two systems hypothesis, this theory is based on the assumption of a relatively transparent relationship between cognitive systems and underlying neural substrates. Behavioural dissociations, however, do not necessarily imply separate neural regions (Plaut, 1995). Likewise a single cognitive system could be supported by more than one neural substrate (Lambon Ralph, McClelland, Patterson, Galton, \& Hodges, 2001). Saffran and Coslett (1998) suggest that the visual analysis, lexical, and semantic systems are duplicated in both hemispheres but that only the left is able to convert the words into speech. There are, however, two other legitimate explanations. The first assumes that a single, whole-word recognition system is supported solely by regions in the left hemisphere. When this, or the visual input to it, are impaired by brain damage, performance reflects residual processing in this compromised

\footnotetext{
${ }^{4}$ Although it should be noted that there is an ongoing debate about the right hemisphere hypothesis for deep dyslexia, with neuropsychological and functional neuroimaging data consistent with both sides of the discussion (Coltheart, 2000; Price et al., 1998).
} 
region rather than the functioning of a secondary system. As we have argued above, the Saffran effect is consistent with partial, graded activation of a single word recognition system. At face value, this single system, left hemisphere-only account does not seem to fit readily with the TMS results reported by Coslett and Monsul (1994). One possible explanation is that the right hemisphere TMS either disrupted high-order visual processing of the stimulus or affected communication of this information to the left hemisphere (JG had a right homonymous hemianopia). In either case, a left hemisphere reading system might have been disordered by right hemisphere TMS because the visual input was disrupted or curtailed. The second, alternative explanation assumes that left and right hemisphere regions are involved in visual word recognition but that these bilateral neural substrates are coupled together, thereby producing a single functional system at the behavioural level of analysis. Even if neural processing is equivalent in both hemispheres, the left-hemisphere structures may be more critical for word recognition if these are preferentially connected to left-lateralised language systems (for neuropsychological evidence and an computational implementation of this idea at the semantic level, see Lambon Ralph et al., 2001). As the bilateral substrates are assumed to combine to produce a single function at the behavioural level, this second alternative hypothesis is also consistent with the notion that the Saffran effect reflects partial, graded activation within a single system, and readily explains the Coslett and Monsul's TMS results.

\section{REFERENCES}

Albert, M. L., Yamadori, A., Gardner, H., \& Howes, D. (1973). Comprehension in alexia. Brain, 96, 317-328.

Behrmann, M., Nelson, J., \& Sekuler, E. (1998a). Visual complexity in letter-by-letter reading: "Pure" alexia is not so pure. Neuropsychologia, 36, 1115-1132.

Behrmann, M., Plaut, D. C., \& Nelson, J. (1998b). A literature review and new data supporting an inter- active account of letter-by-letter reading. Cognitive Neuropsychology, 15, 7-52.

Buxbaum, L. J., \& Coslett, H. B. (1996). Deep dyslexic phenomena in a letter-by-letter reader. Brain and Language, 54, 136-167.

Caplan, L. R., \& Hedley-Whyte, T. (1974). Cueing and memory dysfunction in alexia without agraphia: A case report. Brain, 97, 251-262.

Coltheart, M. (1981). Right-hemisphere reading. Behavioral and Brain Sciences, 4, 67-68.

Coltheart, M. (1998). Seven questions about pure alexia (letter-by-letter reading). Cognitive Neuropsychology, 15, 1-6.

Coltheart, M. (2000). Deep dyslexia is right-hemisphere reading. Brain and Language, 71, 299-309.

Coltheart, M., Patterson, K., \& Marshall, J. C. (1980). Deep dyslexia. London: Routledge \& Kegan Paul.

Coslett, H. B., \& Monsul, N. (1994). Reading with the right hemisphere: Evidence from transcranial magnetic stimulation. Brain and Language, 46, 198-211.

Coslett, H. B., \& Saffran, E. M. (1989a). Evidence for preserved reading in pure alexia. Brain, 112, 327-359.

Coslett, H. B., \& Saffran, E. M. (1989b). Preserved object recognition and reading comprehension in optic aphasia. Brain, 112, 1091-1110.

Coslett, H. B., Saffran, E. M., Greenbaum, S., \& Schwartz, H. (1993). Reading in pure alexia-the effect of strategy. Brain, 116, 21-37.

Damasio, A., \& Damasio, H. (1983). The anatomical basis of pure alexia. Neurology, 33, 1573-1583.

Farah, M. J., \& Wallace, M. (1991). Pure alexia as a visual impairment: A reconsideration. Cognitive Neuropsychology, 8, 313-334.

Feinberg, T., Dyches-Berke, D., Miner, C. R., \& Roane, D. M. (1994). Knowledge, implicit knowledge and metaknowledge in visual agnosia and pure alexia. Brain, 118, 789-800.

Fillingham, J. K., Hodgson, C., Sage, K., \& Lambon Ralph, M. A. (2003). The application of errorless learning to aphasic disorders: a review of theory and practice. Neuropsychological Rehabilitation, 13, 337363.

Franklin, S., Turner, J. M., \& Ellis, A. W. (1992). The $A D A$ comprehension battery. London: Action for Dysphasic Adults.

Goodglass, H., Kaplan, E., \& Weintraub, S. (1983). Boston Naming Test. Philadelphia: Lea \& Febiger.

Howard, D., \& Patterson, K. (1992). The Pyramids and Palm Trees Test: A test of semantic access from words and pictures. Bury St Edmunds, UK: Thames Valley Test Company. 
Kay, J., Lesser, R., \& Coltheart, M. (1992). Psycholinguistic Assessments of Language Processing in Aphasia (PALPA). Hove, UK: Lawrence Erlbaum Associates Ltd.

Kreindler, A., \& Ionasescu, V. (1961). A case of pure word blindness. Journal of Neurology, Neurosurgery and Psychiatry, 24, 275-280.

Lambon Ralph, M. A., \&Ellis, A. W. (1997). "Patterns of Paralexia" revisited: Report of a case of visual dyslexia. Cognitive Neuropsychology, 7, 953-974.

Lambon Ralph, M. A., McClelland, J. L., Patterson, K., Galton, C. J., \& Hodges, J. R. (2001). No right to speak? The relationship between object naming and semantic impairment: Neuropsychological evidence and a computational model. Journal of Cognitive Neuroscience, 13, 341-356.

Landis, T., Regard, M., \& Serrat, A. (1980). Iconic reading in a case of alexia without agraphia caused by a brain tumor: A tachistoscope study. Brain and Language, 11, 45-53.

McClelland, J. L., \& Rumelhart, D. E. (1981). An interactive activation model of context effects in letter perception: Part 1. An account of basic findings. Psychological Review, 88, 375-407.

McKeeff, T. J., \& Behrmann, M. (2004). Pure alexia and covert reading: Evidence from stroop tasks. Cognitive Neuropsychology, 21, 443-458.

McKenna, P., \& Warrington, E. K. (1983). The Graded Naming Test. Windsor, UK: NFER-Nelson.

Morton, J., \& Patterson, K. E. (1980). A new attempt at an interpretation, or, an attempt at a new interpretation. In M. Coltheart, K. E. Patterson, \& J. C. Marshall (Eds.), Deep dyslexia. London: Routledge \& Kegan Paul.

Mycroft, R. H., Behrmann, M., \& Kay, J. (2003). Evidence for a causal role of a visual processing impairment in letter-by-letter reading? Manuscript submitted for publication.

Patterson, K., \& Kay, J. (1982). Letter-by-letter reading: Psychological descriptions of a neurological syndrome. Quarterly Journal of Experimental Psychology: Human Experimental Psychology, 34A, 411-441.
Plaut, D. C. (1995). Double dissociation without modularity: Evidence from connectionist neuropsychology. Journal of Clinical and Experimental Neuropsychology, 17, 291-321.

Plaut, D. C., \& Shallice, T. (1993). Deep dyslexia: A case study of connectionist neuropsychology. Cognitive Neuropsychology, 10, 377-500.

Price, C. J., Howard, D., Patterson, K., Warburton, E. A., Friston, K. J., \& Wise, R. S. J. (1998). A functional neuroimaging description of two deep dyslexic patients. Journal of Cognitive Neuroscience, 10, 303315.

Reuter-Lorenz, P. A., \& Brunn, J. L. (1990). A prelexical basis for letter-by-letter reading: A case study. Cognitive Neuropsychology, 7, 1-20.

Riddoch, M. J., \& Humphreys, G. W. (1992). The Birmingham Object Recognition Battery (BORB). Hove, UK: Lawrence Erlbaum Associates Ltd.

Saffran, E. M., \& Coslett, H. B. (1998). Implicit vs. letter-by-letter reading in pure alexia: A tale of two systems. Cognitive Neuropsychology, 15, 141-166.

Sage, K., Hesketh, A., \& Lambon Ralph, M. A. (2003). Using errorless learning to treat letter-by-letter reading: Contrasting whole vs. letter based therapy. Manuscript submitted for publication.

Shallice, T., \& Saffran, E. (1986). Lexical processing in the absence of explicit word identification: Evidence from a letter-by-letter reader. Cognitive Neuropsychology, 3, 429-458.

Warrington, E. K., \& James, M. (1991). The Visual Object and Space Perception Battery. Bury St Edmunds, UK: Thames Valley Test Company.

Warrington, E. K., McKenna, P., \& Orpwood, L. (1998). Single word comprehension: A concrete and abstract word synonym test. Neuropsychological Rehabilitation, 8, 143-154.

Wilson, B. A., \& Evans, J. J. (1996). Error-free learning in the rehabilitation of people with memory impairments. Journal of Head Trauma Rehabilitation, 11, 54-64. 
401-421.fm Page 422 Friday, February 13, 2004 9:51 AM 